\title{
Mutagenic Effectiveness and Efficiency of Individual and Combination Treatments of Gamma Rays and Ethyl Methanesulfonate in Black Gram [Vigna mungo (L.) Hepper]
}

\author{
Sonu Goyal ${ }^{1}$, Mohammad Rafiq Wani ${ }^{2, *}$, Rafiul Amin Laskar ${ }^{3}$, Aamir Raina $^{4}$, Samiullah Khan $^{1}$ \\ ${ }^{1}$ Mutation Breeding Laboratory, Department of Botany, Aligarh Muslim University, Aligarh-202002, India \\ ${ }^{2}$ Department of Botany, Abdul Ahad Azad Memorial Degree College Bemina-190 018, Cluster University Srinagar, India \\ ${ }^{3}$ Department of Botany, Bahona College, Jorhat-785101, Assam, India \\ ${ }^{4}$ Botany Section, Women's College, Aligarh Muslim University, Aligarh-202002, India
}

Received January 12, 2020; Revised March 31, 2020; Accepted April 19, 2020

Copyright $\bigcirc 2020$ by authors, all rights reserved. Authors agree that this article remains permanently open access under the terms of the Creative Commons Attribution License 4.0 International License

\begin{abstract}
Induced mutagenesis creates new allelic combination of genes without disturbing the basic genomic structure of the plant. Effectiveness relates mutagen dose to mutational events, while mutagenic efficiency shows the proportion of mutations in relation to biological damage in $\mathrm{M}_{1}$ generation. Present investigation was undertaken to assess the effectiveness and efficiency of different individual and combination treatments of gamma rays and EMS in $\mathrm{M}_{2}$ generation of black gram. Mutagenic effectiveness and efficiency were calculated in relation to biological damage in $\mathrm{M}_{1}$ and chlorophyll mutations in $\mathrm{M}_{2}$ generation. The order of mutagenic effectiveness based upon the percent of mutated plant progenies was EMS > gamma rays + EMS $>$ gamma rays. Combination treatments of gamma rays+EMS were found to be the most efficient followed by the individual treatments of EMS and gamma rays in both the varieties. Moderate doses of gamma rays and EMS alone as well as in combination proved more effective and efficient in inducing mutations. Among the varieties, variety Pant U-30 proved more responsive towards mutagenic treatments than the variety T-9. These results not only provide valuable information about mutagenic treatments and germplasm resources of black gram, but also provide guidance for generating black gram mutants through mutation breeding.
\end{abstract}

Keywords Black Gram, Gamma Rays, EMS, Mutagenic Effectiveness, Mutagenic Efficiency, Mutational Rate

\section{Introduction}

Black gram [Vigna mungo (L.) Hepper] also known as urdbean is one of the important self-pollinating diploid crops of the world belonging to family Fabaceae. It is a short duration grain legume having wider adaptability and low input requirement. The crop possesses unique ability to fix atmospheric nitrogen in symbiotic association with Rhizobium bacteria, which not only enables it to meet its own nitrogen requirement but also profits the succeeding crops. Black gram is rich in proteins and has a low concentration of sulphur containing amino acids like methionine and cysteine [1]. Comparatively higher lysine content makes it an excellent complement to cereals vis-à-vis balanced human nutrition [2]. Being rich in quality proteins, amino acids, vitamins and minerals, it is an inseparable ingredient in the diets of vast majority of Indian population. Despite holding prodigious promise, black gram is often pushed to marginal lands with limited input making it prone to number of abiotic stresses causing tremendous loss in productivity. The stumpy productivity is also due to low yield potential and narrow genetic base of the existing cultivars [3]. In these situations, induced mutation may be resorted to develop superior genotypes due to their direct and cumulative effect on genotypic background [4-5].

The response of biological system to physical and chemical mutagens is influenced by numerous biological, environmental and chemical factors. These factors not only modify the effectiveness and efficiency of the mutagens, but also impact the mutational rate [6]. The early information on relative effectiveness and efficiency of 
mutagens helps in optimization and selection of working concentrations/doses that could produce desirable mutations at high rate [7-8]. Although, both effectiveness and efficiency estimates reveal entirely different properties of a mutagen, however collectively they indicate the efficacy of any mutagen [9]. Also, an effective mutagen may not necessarily be an efficient one [10]. Biological parameters of $\mathrm{M}_{1}$ generation are helpful in determining the effectiveness and efficiency of the mutagens, besides identifying the plants with maximum genetic damage that carry high frequency of micro-mutations in subsequent generations [11]. In mutation breeding programs, the selection of effective and efficient mutagens is indispensable to recover high frequency of desirable mutations [12]. Present investigation was undertaken to understand the response of black gram genotypes to both physical and chemical mutagens with a view to identify mutagenic treatments that induce maximum frequency of desirable mutations in $\mathrm{M}_{2}$ generation. The prior information on mutagenic effectiveness and efficiency is considered necessary to recover significant mutations at high rate with lesser lethality in mutation breeding. The estimates of effectiveness and efficiency of the mutagens, in the present study, will reveal the relative efficacy of the applied individual and combined treatments of gamma rays and EMS in black gram genotypes T-9 and Pant U-30, which could facilitate the selection of desirable mutations in subsequent generations and be utilize in other mutation breeding experiments as well.

\section{Materials and Methods}

Field experiment was conducted during the summer season of 2008 and 2009 at Agricultural Farm, Aligarh Muslim University, Aligarh, Uttar Pradesh, India. One set of healthy and dry seeds of varieties T-9 and Pant U-30 of black gram (Vigna mungo (L.) Hepper) were irradiated with 100 to 400 Gy doses of gamma rays from cobalt-60 source at National Botanical Research Institute, Lucknow, India. Another set of 9-hour water presoaked seeds was treated with 0.1 to $0.4 \%$ EMS (ethyl methanesulfonate) prepared in phosphate buffer of $\mathrm{pH}-7$ for 6 hours with constant intermittent shaking at $25 \pm 1^{\circ} \mathrm{C}$ temperature. The seeds were thoroughly washed in running tap water to eliminate the residual mutagen from seed coat after completion of treatment period.

Regarding combination treatments, dry seeds of each variety were firstly irradiated with 200 and $300 \mathrm{~Gy}$ doses of gamma rays followed by the treatment with $0.2 \%$ and $0.3 \%$ of EMS (i.e. $200 \mathrm{~Gy}+0.2 \% \mathrm{EMS}, 300 \mathrm{~Gy}+0.2 \% \mathrm{EMS}$, $200 \mathrm{~Gy}+0.3 \% \mathrm{EMS}, 300 \mathrm{~Gy}+0.3 \% \mathrm{EMS})$. Three replications of 100 -seeds each for every treatment and controls in both the varieties were sown in randomized complete block design (RCBD) to raise $\mathrm{M}_{1}$ generation. The spacing was maintained at $0.30 \mathrm{~m}$ (seed to seed in a row) and $0.60 \mathrm{~m}$ (between the rows) in the field. Recommended agronomic practices were employed for field preparation, seed sowing and subsequent management of the crop. Data on biological parameters such as seedling injury (I), pollen sterility $(\mathrm{S})$ and meiotic aberrations $(\mathrm{Me})$ were recorded in $M_{1}$ generation. Twenty-five healthy seeds from each normal looking $\mathrm{M}_{1}$ plants of different treatments and controls were sown in plant progeny rows to raise $\mathrm{M}_{2}$ generation. Different treatments and controls comprised of 50 progenies. Chlorophyll mutations were recorded in $\mathrm{M}_{2}$ generation when seedlings were 7-15 days old. Mutagenic effectiveness and efficiency of gamma rays, EMS and their combination treatments in $\mathrm{M}_{2}$ generation were calculated as per the formula suggested by Konzak et al. [13] given below:

$$
\text { Rate of mutation }(\mathrm{Mp})=\frac{\text { No. of plant progenies segregating in } \mathrm{M}_{2}}{\text { No. of } \mathrm{M}_{1} \text { plant progenies }} \times 100
$$$$
\text { Mutagenic effectiveness (physical mutagen })=\frac{\text { Rate of mutation }(\mathrm{Mp})}{\text { Dose in }(\mathrm{Gy})}
$$

$$
\text { Mutagenic effectiveness (chemical mutagen })=\frac{\text { Rate of mutation }(\mathrm{Mp})}{\text { concentration } \times \text { duration of treatment }}
$$

Mutagenic effectiveness (combination) $=$

$$
\text { Rate of mutation (Mp) }
$$

Dose of physical mutagen $(\mathrm{Gy}) \times$ concentration of chemical mutagen $\times$ duration of treatment

$$
\text { Mutagenic efficiency }=\frac{\text { Rate of mutation }(\mathrm{Mp})}{{ }^{*} \text { Biological damage in } \mathrm{M}_{1} \text { generation }}
$$


*Biological damage:

For measuring biological damage, three different criteria were used:

i) Injury - i.e. percentage reduction in seedling height $(\mathrm{Mp} / \mathrm{I})$

ii) Sterility - i.e. percentage reduction in pollen fertility $(\mathrm{Mp} / \mathrm{S})$

iii) Meiotic abnormalities - i.e. percentage of meiotic abnormalities $(\mathrm{Mp} / \mathrm{Me})$

Seedling injury was measured in terms of reduction in seedling height with respect to control. Pollen fertility was estimated by staining the pollen grains with $1 \%$ acetocarmine solution. Pollen grains which took stain and had regular shape and outline were considered as fertile, while shrunken, empty and unstained ones were treated as sterile. For meiotic studies, young flower buds were fixed in Carnoy's fluid for 24 hours. Ferric chloride was added as fixative to achieve better staining. After 24 hours of fixation, flower buds were transferred to $70 \%$ ethyl alcohol. Anthers were smeared in 1\% acetocarmine solution and pollen mother cells were examined at various stages of microsporogenesis under Olympus compound microscope.

\section{Results}

Perusal of the data revealed that mutagenic effectiveness and response of black gram varieties to gamma rays, EMS and their combination treatments were varying. In case of gamma rays and EMS, the moderate concentrations were found more effective as compared to lowest and the highest ones in both the varieties (Tables 1,2). In general, EMS proved more effective than combination (gamma rays+EMS) and gamma ray treatments in both the varieties. The estimates of effectiveness ranged from 0.020 to 0.050 in the variety T-9 and 0.040 to 0.060 in the variety Pant U-30 of gamma ray treatments, whereas the effectiveness of EMS treatments ranged from 6.66 to 13.33 and 8.33 to 15.00 in the T-9 and Pant U-30 varieties, respectively. The effectiveness of the combined gamma rays + EMS treatments ranged from 0.041 to 0.058 in the var. T- 9 and 0.051 to 0.062 in the var. Pant U-30 (Tables 1 and 2). The decreasing order of mutagenic effectiveness was found to be EMS, gamma rays + EMS and gamma rays. Mutagenic efficiency was calculated on the basis of seedling injury $(\mathrm{Mp} / \mathrm{I})$, pollen sterility $(\mathrm{Mp} / \mathrm{S})$ and meiotic abnormalities $(\mathrm{Mp} / \mathrm{Me})$ which resulted in highest efficiency at $0.2 \%$ EMS among EMS treatments and 200 Gy $\gamma$ rays among gamma ray treatments in both the varieties. Among the combination treatments, $200 \mathrm{~Gy} \gamma$ rays $+0.2 \%$ EMS in var. T-9 and 300 Gy $\gamma$ rays $+0.2 \%$ EMS in var. Pant U-30 were found to be the most efficient mutagen treatments. Overall, on the basis of seedling injury, pollen sterility and meiotic abnormalities, the efficiency of mutagens in descending order was: gamma rays + EMS $>$ EMS $>$ gamma rays in both the black gram varieties T-9 and Pant U-30. Mutagenic efficiency varied as per the criteria selected for its estimation. The efficiency calculated on the basis of meiotic aberrations was significantly higher as compared to the efficiency calculated on the basis of seedling injury and pollen sterility in both the varieties. Further, mutational rate (MR) based upon injury (I), sterility (S) and meiotic aberrations (Me) was the highest in combination treatments followed by the individual treatments of EMS and gamma rays (Table 3). Assessments on the estimated effectiveness and efficiency in the present study revealed that the genotypic sensitivity of var. Pant U-30 towards the mutagen treatments was higher compared to var. T-9 and thus, var. Pant U-30 responded favorably to the applied mutagen treatments, especially the highest effective EMS treatments.

Table 1. Effectiveness and efficiency of gamma rays, EMS and their combination treatments in $\mathrm{M}_{2}$ generation of black gram variety T-9

\begin{tabular}{|c|c|c|c|c|c|c|c|c|}
\hline \multirow{2}{*}{ Treatment } & \multirow{2}{*}{$\begin{array}{l}\text { \% Seedling } \\
\text { injury (I) }\end{array}$} & \multirow{2}{*}{$\begin{array}{c}\text { \% Pollen } \\
\text { sterility (S) }\end{array}$} & \multirow{2}{*}{$\begin{array}{c}\% \text { Meiotic } \\
\text { abnormalities (Me) }\end{array}$} & \multirow{2}{*}{$\begin{array}{l}\% \text { Mutated plant } \\
\text { progenies }(\mathrm{Mp})\end{array}$} & \multirow{2}{*}{$\begin{array}{l}\text { Mutagenic } \\
\text { effectiveness }\end{array}$} & \multicolumn{3}{|c|}{ Mutagenic efficiency } \\
\hline & & & & & & $\mathrm{Mp} / \mathrm{I}$ & $\mathrm{Mp} / \mathrm{S}$ & $\mathrm{Mp} / \mathrm{Me}$ \\
\hline \multicolumn{9}{|c|}{ Gamma rays } \\
\hline $100 \mathrm{~Gy}$ & 10.41 & 6.72 & 4.53 & 2.00 & 0.020 & 0.19 & 0.30 & 0.44 \\
\hline 200 Gy & 13.42 & 13.08 & 5.76 & 10.00 & 0.050 & 0.74 & 0.76 & 1.74 \\
\hline 300 Gy & 30.34 & 18.35 & 7.85 & 12.00 & 0.040 & 0.39 & 0.65 & 1.53 \\
\hline 400 Gy & 36.96 & 24.56 & 9.66 & 14.00 & 0.035 & 0.38 & 0.57 & 1.45 \\
\hline \multicolumn{9}{|c|}{ EMS } \\
\hline $0.1 \%$ & 8.69 & 6.36 & 2.28 & 4.00 & 6.66 & 0.46 & 0.63 & 1.75 \\
\hline $0.2 \%$ & 13.07 & 13.03 & 5.45 & 16.00 & 13.33 & 1.22 & 1.23 & 2.93 \\
\hline $0.3 \%$ & 21.47 & 17.91 & 6.84 & 16.00 & 8.89 & 0.74 & 0.89 & 2.34 \\
\hline $0.4 \%$ & 34.06 & 24.32 & 8.73 & 20.00 & 8.33 & 0.59 & 0.82 & 2.29 \\
\hline \multicolumn{9}{|c|}{ Gamma rays+EMS } \\
\hline $\begin{array}{c}200 \\
\text { Gy+0.2\% }\end{array}$ & 11.59 & 13.49 & 4.72 & 14.00 & 0.058 & 1.21 & 1.04 & 2.97 \\
\hline $\begin{array}{c}300 \\
\mathrm{~Gy}+0.2 \%\end{array}$ & 16.91 & 19.54 & 6.80 & 20.00 & 0.055 & 1.18 & 1.02 & 2.94 \\
\hline $\begin{array}{c}200 \\
\mathrm{~Gy}+0.3 \%\end{array}$ & 33.47 & 22.78 & 8.59 & 20.00 & 0.055 & 0.60 & 0.88 & 2.33 \\
\hline $\begin{array}{c}300 \\
\text { Gy+0.3\% }\end{array}$ & 41.75 & 28.60 & 10.45 & 22.00 & 0.041 & 0.53 & 0.77 & 2.10 \\
\hline
\end{tabular}


Table 2. Effectiveness and efficiency of gamma rays, EMS and their combination treatments in $\mathrm{M}_{2}$ generation of black gram variety Pant U-30

\begin{tabular}{|c|c|c|c|c|c|c|c|c|}
\hline \multirow{2}{*}{ Treatment } & \multirow{2}{*}{$\begin{array}{l}\text { \% Seedling } \\
\text { injury (I) }\end{array}$} & \multirow{2}{*}{$\begin{array}{l}\text { \% Pollen } \\
\text { sterility (S) }\end{array}$} & \multirow{2}{*}{$\begin{array}{c}\% \text { Meiotic } \\
\text { abnormalities (Me) }\end{array}$} & \multirow{2}{*}{$\begin{array}{l}\% \text { Mutated plant } \\
\text { progenies }(\mathrm{Mp})\end{array}$} & \multirow{2}{*}{$\begin{array}{l}\text { Mutagenic } \\
\text { effectiveness }\end{array}$} & \multicolumn{3}{|c|}{ Mutagenic efficiency } \\
\hline & & & & & & $\mathrm{Mp} / \mathrm{I}$ & $\mathrm{Mp} / \mathrm{S}$ & $\mathrm{Mp} / \mathrm{Me}$ \\
\hline \multicolumn{9}{|c|}{ Gamma rays } \\
\hline $100 \mathrm{~Gy}$ & 9.85 & 7.41 & 4.63 & 4.00 & 0.040 & 0.41 & 0.54 & 0.86 \\
\hline $200 \mathrm{~Gy}$ & 13.04 & 14.48 & 6.29 & 12.00 & 0.060 & 0.92 & 0.83 & 1.91 \\
\hline 300 Gy & 25.91 & 21.61 & 8.51 & 16.00 & 0.053 & 0.62 & 0.74 & 1.88 \\
\hline $400 \mathrm{~Gy}$ & 40.58 & 27.78 & 10.82 & 20.00 & 0.050 & 0.49 & 0.72 & 1.85 \\
\hline \multicolumn{9}{|c|}{ EMS } \\
\hline $0.1 \%$ & 7.25 & 8.20 & 2.73 & 6.00 & 10.00 & 0.83 & 0.73 & 2.20 \\
\hline $0.2 \%$ & 11.88 & 13.58 & 6.08 & 18.00 & 15.00 & 1.51 & 1.32 & 2.96 \\
\hline $0.3 \%$ & 16.81 & 20.77 & 7.20 & 20.00 & 11.11 & 1.19 & 0.96 & 2.78 \\
\hline $0.4 \%$ & 27.54 & 26.90 & 9.38 & 20.00 & 8.33 & 0.73 & 0.74 & 2.13 \\
\hline \multicolumn{9}{|c|}{ Gamma rays+EMS } \\
\hline $\begin{array}{c}200 \\
\mathrm{~Gy}+0.2 \%\end{array}$ & 10.20 & 13.37 & 5.00 & 14.00 & 0.058 & 1.37 & 1.05 & 2.80 \\
\hline $\begin{array}{c}300 \\
\text { Gy+0.2\% }\end{array}$ & 13.91 & 19.81 & 7.45 & 22.00 & 0.062 & 1.58 & 1.11 & 2.95 \\
\hline $\begin{array}{c}200 \\
\mathrm{~Gy}+0.3 \%\end{array}$ & 32.46 & 26.78 & 9.02 & 22.00 & 0.061 & 0.68 & 0.82 & 2.44 \\
\hline $\begin{array}{c}300 \\
\text { Gy+0.3\% }\end{array}$ & 41.16 & 28.75 & 12.54 & 28.00 & 0.051 & 0.68 & 0.97 & 2.23 \\
\hline
\end{tabular}

Table 3. Mutational rate of the mutagens in relation to biological damage of $\mathrm{M}_{1}$ generation in varieties T-9 and Pant U-30 of black gram

\begin{tabular}{|c|c|c|c|c|c|c|}
\hline & \multicolumn{3}{|c|}{ Var. T-9 } & \multicolumn{3}{c|}{ Var. Pant U-30 } \\
\hline Treatment & MRI & MRS & MRMe & MRI & MRS & MRMe \\
\hline Gamma rays & 0.42 & 0.57 & 1.29 & 0.61 & 0.71 & 1.62 \\
\hline EMS & 0.75 & 0.89 & 2.33 & 1.06 & 0.94 & 2.52 \\
\hline Gamma rays + EMS & 0.88 & 0.93 & 2.58 & 1.08 & 0.99 & 2.60 \\
\hline
\end{tabular}

MRI: Mutation rate based on seedling injury MRS: Mutation rate based on pollen sterility MRMe: Mutation rate based on meiotic aberrations

\section{Discussion}

In mutation breeding programs, the knowledge about effectiveness and efficiency of mutagens are imperative for inducing desirable mutations in crop plants. Different workers have reported different mutagenic effectiveness and efficiency in various pulse crops like grass pea [14], lentil [15], cluster bean [16], cowpea [17-18], soybean [19], faba bean [20] and rice bean [21].The gamma rays and EMS are widely used mutagens for inducing viable mutations in crop plants. Gamma rays generally induce cytological and morphological alterations along with physio-chemical effects that directly affect the normal growth and development of the exposed plant [22-23]. Mutagenic effectiveness and efficiency of gamma rays, EMS and their combination treatments were estimated on the basis of frequency of progenies segregating for chlorophyll mutations in $\mathrm{M}_{2}$ generation. In both the varieties, the mutagenic effectiveness and efficiency varied not only between the mutagenic treatments, but also between the mutagens. EMS, individually proved more effective than combination treatments of gamma rays + EMS and gamma rays. EMS was reported as superior mutagen to gamma rays in inducing useful mutations in lentil [24], mungbean [25], chickpea [26], cowpea [27] and urdbean [28]. In this study, the gamma rays and EMS had proved more effective at moderate doses. The decline in mutagenic effectiveness at higher doses indicates that the increase in mutational rate was not proportional with increasing mutagenic doses.

Like effectiveness, the efficiency was generally found higher at moderate or lower mutagenic doses. The greater efficiency of moderate or lower mutagen doses is due to the fact that biological damage generally increases with increasing mutagen doses at a faster rate than the mutations yielded at the same dose [9]. Higher efficiency at lower and intermediate mutagenic doses has been earlier reported in Lens culinaris [29], Vigna mungo [30-31], Vigna radiata [32] and Glycine max [19]. The optimal lower and intermediate treatments of mutagens comparatively induce a tolerable genetic change that leads to successful expression of useful mutations. Mutagenic efficiency 
based upon $\mathrm{Mp} / \mathrm{Me}$ was generally higher as compared to $\mathrm{Mp} / \mathrm{S}$ and $\mathrm{Mp} / \mathrm{I}$. This may be due to the fact that induced meiotic aberrations were comparatively less as compared to the amount of pollen sterility and seedling injury in mutagenized population.

While physical mutagens have been exploited to a greater extent for inducing useful mutations in crop plants and majority of the mutant varieties have been released through them, nevertheless some crop genotypes respond better to chemical mutagens. In such genotypes, appropriate dose and efficient handling of mutated population could yield desirable results vis-à-vis agro-economic traits [11].

\section{Conclusions}

Results show that moderate doses of gamma rays and EMS alone as well as in combination proved more effective and efficient vis-à-vis mutations induced which could be exploited effectively for the improvement of black gram crop.

\section{Significant Statement}

Overview of the results reveal that varieties T-9 and Pant U-30 of black gram proved highly responsive towards the mutagens applied. Intermediate doses of gamma rays and EMS proved more effective and efficient in inducing different mutations. Such mutagenic treatments could be utilized for isolating promising mutant lines with desirable agro-economical traits in various food crops.

\section{Acknowledgements}

The authors are thankful to the Chairman, Department of Botany, Aligarh Muslim University, Aligarh for providing necessary research and laboratory facilities.

\section{Competing Interest}

The authors have declared that no competing interest exists.

\section{REFERENCES}

[1] Srivastava, R. P. and M. Ali, 2004. Nutritional quality of common pulses. Indian Institute of Pulses Research, Kanpur, India.

[2] Tsou, C. S., M. S. Hsu, S. T. Tan and H. G. Park, 1979. Protein quality of mungbean and its improvement. AitoHorticult., 93: 279-289.
[3] Chakravarty, S., 2008. Genetic divergence and character association in mutant cultures of urdbean. M. Sc. thesis, OUAT, Bhubaneswar, Orissa, India.

[4] Baisakh, B., T. R. Das and B. K. Nayak, 2011. Efficacy of physical and chemical mutagenic treatments for micro-mutants in urdbean. J. Food Legumes, 24: 106-109.

[5] Laskar, R. A., M. R. Wani, A. Raina, R. Amin and S. Khan, 2018. Morphological characterization of gamma rays induced multipodding $(\mathrm{mp})$ mutant in lentil cultivar Pant L-406. Int. J. Rad. Biol., 94:1049-1053.

[6] Kodym, A. and R. Afza, 2003. Physical and chemical mutagenesis. Meth. Mol. Biol., 236: 189-203.

[7] Smith, H. H., 1972. Comparative genetic effects of different physical mutagens in higher plants. In: Induced Mutations and Plant Breeding Improvement, IAEA Vienna, 1972, pp. 75-93.

[8] Kumar, R. and S. C. Mani, 1997. Chemical mutagenesis in Manhar variety of rice (Oryza sativa L.). Indian J. Genet., 57(2): 120-126.

[9] Laskar, R. A. and S. Khan, 2017. Mutagenic effectiveness and efficiency of gamma rays and $\mathrm{HZ}$ with phenotyping of induced mutations in lentil cultivars. Inter. Lett. Nat. Sci.,64:17-31.

[10] Gaikwad, N. B. and V. S. Kothekar, 2004. Mutagenic effectiveness and efficiency of ethyl methane sulphonate and sodium azide in lentil (Lens culinaris Medik.). Indian J. Genet., 64(1):73-74.

[11] Wani, A. A., 2009. Mutagenic effectiveness and efficiency of gamma rays, ethyl methane sulphonate and their combination treatments in chickpea (Cicer arietinum L.). Asian J. Plant Sci., 8: 318-321.

[12] Wani, M. R., S. Khan and M. I. Kozgar, 2011. Induced chlorophyll mutations. I. Mutagenic effectiveness and efficiency of EMS, HZ and SA in mungbean. Front. Agric. China, 5: 514-518.

[13] Konzak, C. F., R. A. Nilan, J. Wagner and R. J. Foster, 1965. Efficient chemical mutagenesis. Rad. Bot., 5(Suppl.): 49-70.

[14] Waghmare, V. N. and R. B. Mehra, 2001. Induced chlorophyll mutations, mutagenic effectiveness and efficiency in Lathyrus sativus L. Ind. J. Genet., 61:53-56.

[15] Gaikwad, N. B. and V. S. Kothekar, 2004. Mutagenic effectiveness and efficiency of ethyl methane sulphonate and sodium azide in lentil (Lens culinaris Medik.). Ind. J. Genet., 64:73-74.

[16] Velu, S., L. Mullainathan, D. Arulbalachandran, D. Dhanavel and R. Poongkuzhali, 2007. Effectiveness and efficiency of gamma rays and EMS on cluster bean (Cyamopsis tetragonoloba (L.) Taub.). Crop Res., 34:249-251.

[17] Raina, A., S. Khursheed and S. Khan, 2018. Optimization of mutagen doses for gamma rays and sodium azide in cowpea genotypes. Tren. Biosci., 11: 2386-89.

[18] Dhanavel, D., P. Pavadai, L. Mullainathan, D. Mohana, G. Raju, M. Girija and C. Thilagavathi, 2008. Effectiveness and efficiency of chemical mutagens in cowpea (Vigna unguiculate (L.) Walp). African J. Biotechnol., 7: 


$$
\text { 4116-4117. }
$$

[19] Khan, M. H. and S. D. Tyagi, 2010. Studies on effectiveness and efficiency of gamma rays, EMS and their combination in soybean (Glycine max (L.) Merrill). J. Plant Breed. Crop Sci., 2: $55-58$.

[20] Khursheed, S., A. Raina, R. A. Laskar and S. Khan, 2018. Effect of gamma radiation and EMS on mutation rate: their effectiveness and efficiency in faba bean (Viciafaba L.). Caryologia, 71:397-404.

[21] Mishra, D., L. Bhoi, M. Dash, S. K. Tripathy, T. K. Mishra, M. P. Behera and B. Pradhan, 2019. Mutagenic effectiveness and efficiency of EMS and gamma rays on rice bean (Vigna umbellate Thunb, Ohwi and Ohashi): An underutilized legume crop. Int. J. Chem. Stud., 7: 2060-2064.

[22] Gupta, A. K., S. P. Singh, M. Singh and E. S. Marboh, 2018. Mutagenic effectiveness and efficiency of gamma rays and EMS on cape gooseberry (Physalis peruviana L.). Int. J. Curr. Microbiol. Appl. Sci., 7: 3254-3260.

[23] Julia, T., T. Renuka, H. Nanita and S. Jambhulkar, 2018. Mutagenic effectiveness and efficiency of gamma rays in Indian mustard (Brassica juncea (L.) Czern and Coss). Int. J. Curr. Microbiol. Appl. Sci., 7: 3376-3386.

[24] Solanki I. S. and B. Sharma, 1994. Mutagenic effectiveness and efficiency of gamma rays, ethyl imine and $\mathrm{N}$-nitroso-N-ethyl urea in macrosperma lentil (Lens culinaris Medik). Ind. J. Genet., 54: 72-76.

[25] Singh, A. K., 2007. Mutagenic effectiveness and efficiency of gamma rays and ethyl methane sulphonate in mungbean.
Madras Agric. J., 94: 7-13.

[26] Shah, T. M., J. I. Mirza, M. A. Haq and B. M. Atta, 2008. Induced genetic variability in chickpea (Cicer arietinum L.) II. Comparative mutagenic effectiveness and efficiency of physical and chemical mutagens. Pak. J. Bot., 40: 605-613.

[27] Girija, M. and D. Dhanavel, 2009. Mutagenic effectiveness and efficiency of gamma rays, ethyl methane sulphonate and their combined treatments in cowpea (Vigna unguiculata (L.) Walp). Global J. Mol. Sci., 4: 68-75.

[28] Goyal, S., M. R. Wani and S. Khan, 2019. Frequency and spectrum of chlorophyll mutations induced by single and combination treatments of gamma rays and EMS in urdbean. Asian J. Biol. Sci., 12: 156-163.

[29] Wani, M. R., 2017. Induced chlorophyll mutations, comparative mutagenic effectiveness and efficiency of chemical mutagens in lentils (Lens culinaris Medik). Asian J. Plant Sci., 16: 221-226.

[30] Deepalakshmi, A. J. and C. R. Anandakumar, 2003. Efficiency and effectiveness of physical and chemical mutagens in urdbean (Vigna mungo (L.) Hepper). Madras Agric. J., 90: 485-489.

[31] Sharma, S. K., S. Ritu and D. Pandey, 2005. Studies on mutagen sensitivity, effectiveness and efficiency in urdbean (Vigna mungo L.). Ind. J. Genet.,65: 20-22.

[32] Goyal, S., S. Khan, Alka and R. Perveen, 2009. A comparison of mutagenic effectiveness and efficiency of EMS, SA and gamma rays in mungbean. Ind. J. Appl. Pure Biol., 24: 125-128. 